\title{
Comment on: Carotid-cavernous fistula: current concepts in aetiology, investigation and management
}

\author{
Taras Gout $^{1} \cdot$ Tufail Patankar $^{2} \cdot$ Nabil El-Hindy ${ }^{2} \cdot$ George Kalantzis $^{2}$
}

Received: 8 April 2018 / Accepted: 23 April 2018 / Published online: 18 May 2018

(c) The Royal College of Ophthalmologists 2018

We have read with great interest the article by Henderson and Miller regarding the endovascular management of dural carotid-cavernous fistulas with a transvenous approach via the superior ophthalmic vein [1]. An anterior orbitotomy allows the superior ophthalmic vein to be identified, and a venous catheter inserted and advanced into the cavernous sinus with a success rate for transvenous procedures reported at around $80 \%$ [1]. Carotid-cavernous fistulas are associated with a dilatation of the superior ophthalmic vein, however, challenges to their identification and cannulation arise in cases of small, fragile, anomalous or thrombosed veins [2].

Based on our experience, we would like to report the use of an intraoperative Valsalva manoeuvre to assist cannulation of the superior ophthalmic vein. A 60-year-old gentleman underwent endovascular repair with a transvenous approach via the superior ophthalmic vein of a dural carotid-cavernous fistula. An anterior orbitotomy approach identified the superior ophthalmic vein, although cannulation proved challenging as the vein was small and fragile. An intraoperative anaesthetist controlled Valsalva manoeuvre was performed, which produced a prominent dilatation of the vein and enabled a successful cannulation. This technique may also be used to identify a small or anomalous superior ophthalmic vein.

Head and neck surgery may be associated with lifethreatening post-operative bleeding. Subsequently, numerous publications discuss intraoperative Valsalva manoeuvre and Trendelenburg positioning to assist identification of bleeding vessels [3, 4]. To our knowledge, this is the first report of intraoperative Valsalva manoeuvre used to assist ophthalmic vein cannulation, and hope this may be considered in similar challenging cases.

\section{Compliance with ethical standards}

Conflict of interest The authors declare that they have no conflict of interest.

\section{References}

1. Henderson AD, Miller NR. Carotid-cavernous fistula: current concepts in aetiology, investigation and management. Eye. 2018;32:164-72.

2. Leibovitch I, Modjtahedi S, Duckwiler GR, Goldberg RA. Lessons learned from difficult or unsuccessful cannulations of the superior ophthalmic vein in the treatment of cavernous sinus dural fistulas. Ophthalmology. 2006;113:1220-6.

3. Moumoulidis I, Martinez Del Pero M, Brennan L, Jani P. Haemostasis in head and neck surgical procedures: Valsalva manoeuvre versus Trendeleburg tilt. Ann R Coll Surg Engl. 2010;92:292-4.

4. Ozdemir M, Makay O, Icoz G, Akyildiz M. What adds Valsalva maneuver to haemostasis after Trendelenburg's positioning during thyroid surgery? Gland Surg. 2017;6:433-6.
George Kalantzis

george.kalantzis@nhs.net

York Teaching Hospital, York, UK

2 Leeds Teaching Hospitals NHSFT, Leeds, UK 


\title{
Reply to 'Comment on: Carotid-cavernous fistula: current concepts in aetiology, investigation and management'
}

\author{
Amanda D. Henderson ${ }^{1} \cdot$ Neil R. Miller ${ }^{1}$ \\ Received: 23 April 2018 / Accepted: 23 April 2018 / Published online: 22 May 2018 \\ (c) The Royal College of Ophthalmologists 2018
}

We appreciate the comments by Gout et al. [1] We agree that some superior ophthalmic veins are extremely fragile and difficult to cannulate, even with the available microcatheters (see supplemental video). We also agree that performing a Valsalva maneuver may make it easier to insert the microcatheter into the vessel. One still must be careful not to perforate the vessel as the catheter is advanced, as catastrophic visual complications can result, as emphasized in our manuscript and in the paper by Leibovitch et al., which we (and Gout et al.) have referenced [2].

Electronic supplementary material The online version of this article (https://doi.org/10.1038/s41433-018-0113-4) contains supplementary material, which is available to authorized users.

Neil R. Miller

nrmiller@jhmi.edu

1 Division of Neuro-Ophthalmology, Wilmer Eye Institute, Johns Hopkins School of Medicine, Baltimore, MD, USA

\section{Compliance with ethical standards}

Conflict of interest The authors declare that they have no conflict of interest.

\section{References}

1. Gout T, Patankar T, El-Hindy N, Galantzis G. Carotid-cavernous fistula: current concepts in aetiology, investigation and management. Eye. 2018.

2. Leibovitch I, Modjtahedi S, Duckwiler GR, Goldberg RA. Lessons learned from difficult or unsuccessful cannulations of the superior ophthalmic vein in the treatment of cavernous sinus dural fistulas. Ophthalmology. 2006;113:1220-6.

\section{Electric cataracts: a cause of bilateral blindness in Kashmir}

\author{
Rayees Sofi ${ }^{1} \cdot$ Tariq Qureshi ${ }^{1} \cdot$ Viney Gupta $\mathbb{D}^{2}$
}

Received: 27 February 2018 / Accepted: 28 February 2018 / Published online: 23 May 2018

(c) The Royal College of Ophthalmologists 2018

\section{Viney Gupta}

gupta_v20032000@yahoo.com

1 Government Medical College Srinagar, Srinagar, Jammu and Kashmir, India

2 Dr. Rajendra Prasad Centre for Ophthalmic Sciences, All India Institute of Medical Sciences, New Delhi, India
Electrical injury is not uncommon as many people come into contact with electricity on daily basis. However only few cases of electrical cataract have been reported because very few patients survive after a high electric voltage, that is needed to induce cataract [1-3]. Most of the cases of electrical injury have no visual complaints in the early 
period but their visual acuity decreases after a few months of injury with the development of cataract [2, 4].

We saw six young patients in Kashmir valley in India over 2013-2017 developing bilateral electrical cataracts at our tertiary care centre. Three patients (labourers) had electrical injury while at work, whereas the other three had high voltage wires falling on them while walking on the street. In this part of the world, electricity runs via overhead wires that are uninsulated, increasing the chances of such electrical injury. All these patients were under 40 years of age. The cataracts formed were soft but total cataracts that could be easily aspirated providing good visual gain. All the patients had an entry and exit wound. One of the patients required an amputation of his hand while another had total loss of his ear lobe at the exit wound.

Electrical cataracts causing bilateral blindness at a young age is of great concern, as what we may be seeing is only part of a much bigger problem that needs to be tackled at its roots. Our apprehension lies in that such injuries are totally avoidable if an extra amount of care is taken while working at such high voltage currents and if overhead wires are properly insulated.

Electrical insults to the human body can result in a wide range of ocular injuries with resultant ocular complications An incidence of $6.2 \%$ of cataracts is reported following electric injury [4].

Korn and Kikkawa [5] describe a patient post electrical injury with bilateral cataracts and optic atrophy with widespread macular pigment disruption who later developed retinal detachment causing permanent visual impairment. While none of our patients had retinal complications, one needs to follow up these cases over long term due to the potential of retinal detachments later on.

For the state of Kashmir which harbours one of the highest rates of blindness in India and is riddled with social conflict, government efforts need to be harnessed to prevent this public health issue. What we observed at our apex eye care centre could just be the tip of the iceberg.

Funding No financial support has been received by any authors and none of the authors has any proprietary interest in the subject matter presented

\section{Compliance with ethical standards}

Conflict of interest The authors declare that they have no conflict of interest.

\section{References}

1. Raina UK, Tuli D. Bilateral electric cataract. Br J Ophthalmol. 1999;83:1091.

2. Long JC. Electrical cataract: report of three cases. Am J Ophthalmol. 1996;61:1235-9.

3. Boozalis GT, Purdu GF, Hunt JL, Mcculley JP. Ocular changes from electric burn injuries. A literature revive and report of cases. J Burn Care Rehab. 1991;12:458-62.

4. Saffle JR, Crandall A. Warden GD.Cataracts: a long term complication of electrical injury. J Trauma. 1985;25:17-21.

5. Korn BS, Kikkawa DO. Images in clinical medicine. Ocular manifestation of electrical burn. N Engl J Med. 2014;23:e6.370.

\section{Comment on 'Overprescribing of antibiotics by UK ophthalmologists'}

\section{Carl David Morsman ${ }^{1}$}

Received: 1 April 2018 / Accepted: 23 April 2018 / Published online: 23 May 2018

(c) The Royal College of Ophthalmologists 2018

Carl David Morsman

David.Morsman@hhft.nhs.uk

1 Department of Ophthalmology, Basingstoke and North Hampshire Hospital, Aldermaston Road, Basingstoke RG24 9NA, UK
I entirely agree with the recommendations made by Fayers et al. [1] to reduce antibiotic prescribing for chalazia and eyelid surgery but wonder whether the general title of the paper should have covered numerous other situations such as prophylaxis in viral conjunctivitis and corneal abrasion. One of the most common doubtful uses however is 
following cataract surgery. NICE guidance [2] comments that postoperative topical antibiotic prescribing is "part of standard practice" without advising it and recommending further research. Overall, 97\% of ASCRS members use them [3], and the version of Medisoft EPR used at my institution produces a prescription for a 2 week 'course' of antibiotics without prompting the surgeon to confirm the default position.

According to The Scottish Intercollegiate Guidelines Network [4] which covers ophthalmic as well as other disciplines of surgery, appropriate surgical prophylaxis is usually defined as a single peroperative dose though this can be extended to a maximum of $24 \mathrm{~h}$ for orthopaedic implants. Prolonged courses are thought to be unhelpful or deleterious though evidence for this in cataract surgery is lacking. Herrinton et al. [5] found that addition of postoperative topical antibiotics to an intracameral application increased the incidence of endophthalmitis (odds ratio of 1.6) though they commented on a possible lack of significance with only 11,000 patients in the intracameral only group.

The NICE request for further research is well made but surgeons can be reassured that endophthalmitis will not become much more common if they discontinue this probably inappropriate antibiotic prescribing as I did 15 years ago. Doing so could clarify this topic through our national dataset.

\section{Compliance with ethical standards}

Conflict of interest The authors declare that they have no conflict of interest.

\section{References}

1. Fayers T, et al. Overprescribing of antibiotics by UK ophthalmologists. Eye. 2018;32:240-2.

2. Cataracts in adults: management. National Institute for Health and Care Excellence. 2017. https://www.nice.org.uk/guidance/ng77. Accessed 16 Mar 2018.

3. Chang DF, et al. Antibiotic prophylaxis of postoperative endophthalmitis after cataract surgery: Results of the 2014 ASCRS member survey. J Cataract Refract Surg. 2015;41:1300-5.

4. SIGN 104 Antibiotic prophylaxis in surgery. Scottish Intercollegiate Guidelines Network. 2014. www.sign.ac.uk/sign-104-a ntibiotic-prophylaxis-in-surgery.html. Accessed 16 Mar 2018.

5. Herrinton LJ, et al. Comparative effectiveness of antibiotic prophylaxis in cataract surgery. Ophthalmology. 2016;123:287-94.

\section{Endophthalmitis in patients co-infected by HIV and sporotrichosis: a systematic review of published case reports}

Electronic supplementary material The online version of this article (https://doi.org/10.1038/s41433-018-0145-9) contains supplementary material, which is available to authorized users.

\footnotetext{
Max Carlos Ramírez-Soto

maxcrs22@gmail.com

mramirez@cienciactiva.gob.pe

1 School of Public Health and Administration, Universidad Peruana Cayetano Heredia, Lima, Peru

2 Fondo Nacional de Desarrollo Científico y Tecnológico y de Innovación Tecnológica (FONDECYT), CONCYTEC, Lima, Peru

3 Mycology department, Hospital General de México, Mexico City, Mexico

4 Dermatology department, Hospital General de México, Mexico City, Mexico

5 Internal Medicine department, Hospital General de Zona 29, Instituto Mexicano del Seguro Social, Mexico City, Mexico
}

\author{
Max Carlos Ramírez-Soto $\mathbb{1}^{1,2} \cdot$ Alexandro Bonifaz ${ }^{3,4}$. \\ Andrés Tirado-Sánchez ${ }^{4,5}$
}

Received: 4 April 2018 / Accepted: 26 April 2018 / Published online: 7 June 2018

(c) The Royal College of Ophthalmologists 2018

Sporotrichosis cases in HIV-infected patients have increased in recent decades [1, 2]. A systematic review has showed that, compared with exogenous endophthalmitis caused by Sporothrix, endogenous endophthalmitis (EE) is more common in HIV-infected patients from hyperendemic areas [3]. These findings suggest that HIV infection may predispose to an increased risk for progression to EE in patients with sporotrichosis [3]. However, EE rate and factors associated with this condition in patients co-infected by HIV and sporotrichosis has not been described. Here we 
investigate this rate and factors associated with this condition using data collected from the published literature.

\section{Methods}

We performed a systematic review in multiple databases (including PubMed, MEDLINE, EMBASE, and Scopus) to Dec 20, 2017, to identify all case reports and case series describing patients co-infected by HIV and sporotrichosis. This systematic review was performed in accordance with the Preferred Reporting Items for a Systematic Review and Meta-analysis (PRISMA) [4]. Our inclusion criteria included patients with sporotrichosis confirmed by positive Sporothrix culture from tissue or clinical samples and infection by HIV confirmed by laboratory tests. Patients were classified as having EE if they had intraocular inflammation with a positive intraocular Sporothrix culture

Table 1 Demographics and clinical characteristics from patients HIV/ sporotrichosis co-infected with and without $\mathrm{EE}$

\begin{tabular}{|c|c|c|c|}
\hline Characteristic & EE group & $\begin{array}{l}\text { Non-EE } \\
\text { group }\end{array}$ & $p$ Value \\
\hline No. $(\%)$ of patients & $5(7.7 \%)$ & $60(92.3 \%)$ & \\
\hline \multicolumn{4}{|l|}{ Age, y } \\
\hline Mean (SE) & $33(2.9)$ & $37.5(1.4)$ & $0.347 *$ \\
\hline Range & $25-43$ & $11-49$ & NA \\
\hline \multicolumn{4}{|l|}{ Sex, No. $(\%)$ of patients } \\
\hline Male & $5(100 \%)$ & $51(85 \%)$ & $0.351 * *$ \\
\hline Female & $0(0.0 \%)$ & $9(15 \%)$ & \\
\hline \multicolumn{4}{|l|}{ Please of residence } \\
\hline Hyperendemic $^{\mathrm{a}}$ & $4(80 \%)$ & $35(58.3 \%)$ & $0.342 * *$ \\
\hline Non-hyperendemic & $1(20 \%)$ & $25(41.7 \%)$ & \\
\hline \multicolumn{4}{|c|}{ Sporotrichosis clinical form, No. (\%) of patients } \\
\hline Disseminated & $5(100 \%)$ & $32(53.3 \%)$ & $0.393 * *$ \\
\hline Disseminated cutaneous & $0(0.0 \%)$ & $13(21.7 \%)$ & \\
\hline Lymphocutaneous & $0(0.0 \%)$ & $8(13.3 \%)$ & \\
\hline Fixed cutaneous & $0(0.0 \%)$ & $3(5.0 \%)$ & \\
\hline Others & $0(0.0 \%)$ & $4(6.7 \%)$ & \\
\hline $\begin{array}{l}\text { Mean CD4 count, cell/uL } \\
{\text { (range) })^{\mathrm{b}}}\end{array}$ & $\begin{array}{l}168.25 \\
(25-600)\end{array}$ & $\begin{array}{l}184.45 \\
(6-1100)\end{array}$ & $0.898 *$ \\
\hline \multicolumn{4}{|l|}{ Organism, No. (\%) } \\
\hline Sporothrix schenckii & $2(40 \%)$ & $59(98.3 \%)$ & $0.0001 * *$ \\
\hline Sporothrix brasiliensis & $3(60 \%)$ & $0(0.0 \%)$ & \\
\hline Sporothrix spp. & $0(0.0 \%)$ & $1(1.7 \%)$ & \\
\hline
\end{tabular}

$E E$ endogenous endophthalmitis, $S E$ standard error

$* t$-Student

$* * \chi 2$ test

aHyperendemic: Brazil, an area known to have a high rate of sporotrichosis

${ }^{b}$ Median CD4 + count was obtained from four patients with EE and 47 patients without EE. or positive Sporothrix culture from tissue or clinical samples (skin biopsy and/or exudate, cerebrospinal fluid, sputum, blood and synovial fluid). Patients demographic (gender, age and please residence), clinical characteristics (sporotrichosis clinical form, and the median CD4+ T-cell lymphocyte count) and microbial data were recorded. To assess the independent association between EE and characteristics of these patients, we compared patients with and without EE using univariate analysis with $\chi^{2}$ and $t$ tests. Statistical analysis was conducted using the PSS software (Chicago, IL, USA).

\section{Results}

A total of 43 publications reporting 65 individual case reports were included for data extraction and analysis (supplementary information) [1, 3, 5-7]. The EE rate in patients co-infected by HIV and sporotrichosis was $7.7 \%$ (7 eyes of 5 patients). Choroiditis was the most common clinical manifestation (5 eyes), followed by retinochoroiditis ( 1 eye), and granulomatous uveitis (1 eye). Culture of ocular specimens was Sporothrix positive in 1 of 5 patients with EE. All patients with EE had disseminated sporotrichosis. S. schenckii was causative fungus from all cases of the non-EE group $(P<0.0001)$ (Table 1). There were no independent association in demographic characteristics, sporotrichosis clinical form, and the median CD4+ T-cell lymphocyte count between the patients with and without EE $(P>0.05)$ (Table 1).

\section{Discussion}

Endophthalmitis due to Sporothrix species is extremely rare, with only few published case reports. This could have influenced on EE rate in patients co-infected by HIV and sporotrichosis, and our study could have either underestimated or overestimated the EE rate, resulting in possible bias. Therefore, EE rate in patients co-infected by HIV and sporotrichosis found in this study was low, it is less likely to recover Sporothrix fungus of ocular specimens, and there were no association between the clinical factors and EE. Although these findings limited, the development of $\mathrm{EE}$ only seems to be one of the manifestations of disseminated sporotrichosis in patients HIV-infected, therefore, betterdesigned studies with a well-selected population are essential.

\section{Acknowledgements}

Author contributions All authors had full access to all the data in the study and takes responsibility for the integrity of the data and the 
accuracy of the data analysis. Study concept and design: All authors. Acquisition, analysis, or interpretation of data: All authors. Drafting of the manuscript: All authors. Critical revision of the manuscript for important intellectual content: Ramírez-Soto, Bonifaz, TiradoSánchez. Statistical analysis: Ramírez-Soto

\section{Compliance with ethical standards}

Conflict of interest The authors declare that they have no conflict of interest.

\section{References}

1. Moreira JA, Freitas DF, Lamas CC. The impact of sporotrichosis in HIV-infected patients: a systematic review. Infection. 2015;43 (3):267-76.

2. Freitas DFS, Valle ACFd, da Silva MBT, Campos DP, Lyra MR, de Souza RV, et al. Sporotrichosis: an emerging neglected opportunistic infection in HIV-infected patients in Rio de Janeiro, Brazil. PLoS Negl Trop Dis. 2014;8(8):e3110.
3. Ramírez Soto MC. Differences in clinical ocular outcomes between exogenous and endogenous endophthalmitis caused by Sporothrix: a systematic review of published literature. Br J Ophthal. 2017. https://doi.org/10.1136/bjophthalmol-2017-310581.

4. Liberati A, Altman DG, Tetzlaff J, Mulrow C, Gøtzsche PC, Ioannidis JP, et al. The PRISMA statement for reporting systematic reviews and meta-analyses of studies that evaluate healthcare interventions: explanation and elaboration. BMJ. 2009;339:b2700.

5. Biancardi AL, Freitas DF, Valviesse VR, Andrade HB, de Oliveira $\mathrm{MM}$, do Valle AC, et al. Multifocal choroiditis in disseminated sporotrichosis in patients with HIV/AIDS. Retin Cases Brief Rep. 2017;11(1):67-70.

6. Silva-Vergara ML, de Camargo ZP, Silva PF, Abdalla MR, Sgarbieri RN, Rodrigues AM, et al. Disseminated Sporothrix brasiliensis infection with endocardial and ocular involvement in an HIV-infected patient. Am J Trop Med Hyg. 2012;86(3):477-80.

7. Lyra MR, Nascimento ML, Varon AG, Pimentel MI, Antonio LdeF, Saheki MN, et al. Immune reconstitution inflammatory syndrome in HIV and sporotrichosis coinfection: report of two cases and review of the literature. Rev Soc Bras Med Trop. 2014;47 (6):806-9. 